\title{
LA RYNX.
}

Rudolf Landesberg.-A Piece of Cartilage Impacted in the Pyriform Fossa. "Monatsschrift für Ohrenheilkunde," December, 1905.

The patient was a man, aged sixty-three. When first seen he had been suffering from great pain on swallowing for a month. The pain radiated to both ears and made the swallowing, even of fluids, a matter of great difficulty; there was considerable dyspnoa. The pharyngeal mucous membrane was congested, the epiglottis much thickened, especially on the right side, the pyriform fossa was filled with a motionless, uneven tumour, and the right arytenoid cartilage, aryteno-epiglottidean fold, and ventricular band were much swollen. Only the extreme edge of the right vocal cord was visible. The right half of the larynx was immobile. Some small glands could be felt at the posterior edge of the sterno-mastoid. A diagnosis of malignant neoplasm, probably sarcoma, was made. A small piece of the right ventricular band was excised and examined histologically, but only normal tissue was found. The patient went home, but returned four weeks later. The pain was now very acute. The swelling of the right side of the larynx had much diminished, but the pyriform fossa was covered with a greenish-brown slough, which extended on to the right pharyngeal wall. A very offensive odour escaped from the patient's throat. With a pair of forceps a fotid piece of necrotic tissue was removed, exposing a cylindrical body, which when removed proved to be a piece of cartilage $(2 \mathrm{~cm} . \times 3 \mathrm{~mm}$.). The patient felt at once relieved and lost his dyspnœa. The septic inflammation of the pyriform fossa continued for some time, with occasional acute swelling of the right side of the larynx. A few days after the operation there was a very severe hæmorrhage from the pyriform fossa. Ultimately the patient made a good recovery ; the right vocal cord, however, remained immobile, and some thickening of the arytenoid cartilage and the ventricular band persisted.

Knowles Renshaw.

Saunders, E. W. (St. Louis).-A Plea for the more timely use of Intubation in Laryngeal Stenosis, and for the use of Tracheotomy in certain Neglected Cases. “"Archives of Pediatrics,” February, 1906.

The author grounds his plea regarding intubation upon the dangers (1) of pseudo-membrane, (2) of swelling of the tissues, (3) of laryngospasm, (4) of retained secretions. Tracheotomy, he thinks, should be performed in " unrelenting spasm of the glottis," in tracheal or tracheobronchial diphtheria, in cases with extensive membrane in the fauces, and in cases apparently moribund.

Macleod Yearsley.

\section{EAR.}

Delstanche, E.-Mastoiditis and Furunculosis. "La Presse Oto-laryngologique Belge," March, 1906.

Two cases with similar symptoms are contrasted-one an abscess in the soft parts covering the mastoid process, not connected with disease of the ear, the other a case of acute mastoiditis.

The diagnosis in such cases is sometimes doubtful until a mastoid incision is made, which shows the real condition. Chichele Nourse. 